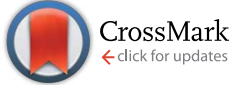

Cite this: RSC Adv., 2016, 6, 49806
Received 24th February 2016

Accepted 11th May 2016

DOI: 10.1039/c6ra04856k

www.rsc.org/advances

\section{Antioxidant and dual dose-dependent antigenotoxic and genotoxic properties of an ethanol extract of propolis $\uparrow$}

\author{
M. Cruz, ${ }^{a}$ P. Antunes, ${ }^{b}$ L. Paulo, ${ }^{b}$ A. M. Ferreira, ${ }^{c}$ A. Cunha, ${ }^{a}$ C. Almeida-Aguiar ${ }^{a}$ \\ and R. Oliveira*a
}

Propolis is a resinous product made by honeybees from plant-derived materials, with high content of polyphenols associated to several beneficial bioactivities with potential use as a natural food additive for preservation and as a functional food ingredient. A Portuguese propolis ethanol extract (C.EE) protected Saccharomyces cerevisiae cells from loss of viability upon exposure to $\mathrm{H}_{2} \mathrm{O}_{2}$, both in co- and in preincubation experiments. Results obtained with the comet assay suggest that lower concentrations are antigenotoxic while at higher concentrations a genotoxic effect prevails, which correlates with the cytotoxicity of high concentrations of C.EE. Flow cytometry analysis with dichlorofluorescein indicates that C.EE induced intracellular antioxidant activity in vivo. Overall the results suggest that C.EE is antigenotoxic but is also toxic at higher concentrations. This dual effect could be explained by the presence of compounds known to interfere with DNA synthesis and/or cell proliferation, such as caffeic acid phenethyl ester (CAPE) and chrysin, together with antioxidants, like kaempferol, pinobanksin and pinocembrin.

\section{Introduction}

Propolis is a resinous mixture produced by honeybees from exudates of buds and the bark of plants such as poplar (Populus spp.), birch (Betula spp.), beech (Fagus spp.), horse chestnut (Aesculus hippocastanum), alder (Alnus spp.), Brazilian rosemary (Baccharis dracunculifolia), eucalyptus (Eucalyptus spp.) and Brazilian pine (Araucaria angustifolia). It is generally accepted that propolis is used in the hive, mainly as a construction and antiseptic material, for repairing mechanical damage and avoiding microbial infections.

Propolis is chemically diverse and its composition varies geographically according to the flora and climate, the season of collection, as well as with the species of the producing bees. ${ }^{1}$ Propolis compounds belong to very different chemical groups, such as polyphenols (flavonoids, including flavones, flavonones, flavonols, dihydroflavonols and chalcones), phenolic acids and their esters, terpenoids, steroids and amino acids. ${ }^{2}$

${ }^{a}$ Centre for the Research and Technology of Agro-Environmental and Biological Sciences (CITAB), Department of Biology, University of Minho, Campus de Gualtar, 4710-057 Braga, Portugal. E-mail: ruipso@bio.uminho.pt; Fax: +351 253604319; Tel: +351253601512

${ }^{b}$ Centro de Apoio Tecnológico Agro Alimentar (CATAA), Zona Industrial de Castelo Branco, Rua A, 6000-459 Castelo Branco, Portugal

${ }^{c}$ Chemistry Research Center (CQVR), University of Trás-os-Montes e Alto Douro, Quinta de Prados, 5000-801 Vila Real, Portugal

$\dagger$ Electronic supplementary information (ESI) available. See DOI: 10.1039/c6ra04856k
Most of these compounds, in particular phenolics such as caffeic acid derivatives and flavonoids, have been associated with propolis biological activities, namely antimicrobial, ${ }^{3}$ cytotoxic and hepatoprotective, ${ }^{2}$ radioprotective, antimutagenic, ${ }^{4}$ antioxidant $^{5}$ and as scavenger of free radicals. ${ }^{2}$

The widely recognized properties of propolis have been promoting its extensive use in nutraceutics, cosmetics and health care. In addition, the consumers' widely good acceptance of the incorporation of natural products in foods and medicines increases the potential use of propolis as food functional ingredient and as preservative. Hence, propolis has been attracted the attention of researchers to formulate new natural food functional ingredients ${ }^{6,7}$ and was also included in several food products with beneficial effects as preservative. ${ }^{8,9}$ Still in many countries, honey producers have disregarded propolis due to low yields and lack of knowledge of its economic potential as a valuable co-product. Hence, the demonstration of bioactivities but also cell-protective properties for the development of functional foods and health-care products based on propolis are a major goal.

The antioxidant activity of flavonoids of propolis, in samples from very different provenances, has been reported as a mechanism of protection of genomic DNA against reactive oxygen species. ${ }^{\mathbf{1 0 , 1 1}}$ Also, genotoxic effects of propolis extracts and of some of their constituents can be found in the literature, ${ }^{\mathbf{1 2}}$ having been attributed to the pro-oxidant activity of flavonoids. ${ }^{13}$ This pro-oxidant activity has been shown to be directly dependent on concentration and is mediated by increased 
production of superoxide, hydrogen peroxide and hydroxyl radical in human lymphocytes. ${ }^{\mathbf{1 4}}$ Therefore, it is conceivable that propolis extracts might have concentration-dependent antagonistic effects, owing to the considerable amount and diversity of flavonoids as constituents. To investigate these effects on genome integrity we studied the antigenotoxic, genotoxic and antioxidant capacity of an ethanol extract of a propolis sample collected in 2010, in the region of Côa (Beira Alta, Portugal), using the eukaryotic experimental model Saccharomyces cerevisiae.

\section{Experimental}

\section{Yeast strain, media and growth conditions}

In all experiments the haploid Saccharomyces cerevisiae strain

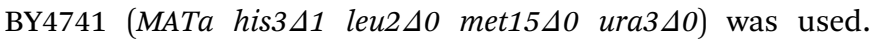
Cultures were grown on liquid YPD medium $(1 \% \mathrm{w} / \mathrm{v}$ yeast extract, $1 \% \mathrm{w} / \mathrm{v}$ peptone and $2 \% \mathrm{w} / \mathrm{v}$ glucose), in an orbital shaker at $30{ }^{\circ} \mathrm{C}$ and $200 \mathrm{rpm}$. Growth was monitored by optical density at $600 \mathrm{~nm}\left(\mathrm{OD}_{600}\right)$.

\section{Propolis ethanol extract}

Raw propolis was collected in August 2010 from an apiary set in the region of Côa (Beira Alta, Portugal). A $29 \mathrm{~g}$ propolis sample was incubated with $100 \mathrm{~mL}$ absolute ethanol in an orbital shaker at $100 \mathrm{rpm}$, at room temperature, in the dark, for $24 \mathrm{~h}$. The solution was then filtered (Whatman nr. 4) and the residue was re-dissolved in $100 \mathrm{~mL}$ absolute ethanol and extracted again. This procedure was repeated three times. The filtrates were pooled and dried in a rotary evaporator (Buchi RE 121), at $40{ }^{\circ} \mathrm{C}$, under vacuum and gentle rotation (50 rpm), yielding the ethanol extract of Côa propolis (C.EE), which was stored in the dark at $4{ }^{\circ} \mathrm{C}$ until use. Working solutions at the desired concentrations were prepared in ethanol immediately before use.

\section{Viability assays}

Yeast cells from exponentially growing cultures were harvested by 2 min centrifugation at $6000 \times g, 4{ }^{\circ} \mathrm{C}$, washed twice with the same volume of sterilized deionized $\mathrm{H}_{2} \mathrm{O}$ at $4{ }^{\circ} \mathrm{C}$ and suspended

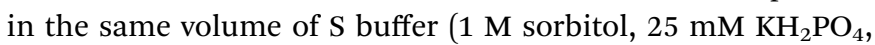
$\mathrm{pH}$ 6.5). The suspension was incubated at $30^{\circ} \mathrm{C}, 200 \mathrm{rpm}$, in the presence of $5 \mathrm{mM} \mathrm{H}_{2} \mathrm{O}_{2}$, after which aliquots were harvested along time, serially diluted to $10^{-4}$, spread on YPD plates and incubated at $30{ }^{\circ} \mathrm{C}$ for $48 \mathrm{~h}$. The percentage of colony-forming units (CFUs) was calculated at each time-point taking as reference the number of colonies obtained before the addition of $\mathrm{H}_{2} \mathrm{O}_{2}$. In pre-incubation experiments, cells were incubated with C.EE for $20 \mathrm{~min}$, at $30{ }^{\circ} \mathrm{C}, 200 \mathrm{rpm}$ and were washed and suspended in $\mathrm{S}$ buffer, as described above. In co-incubation experiments C.EE and $\mathrm{H}_{2} \mathrm{O}_{2}$ were added to the suspension simultaneously. In post-incubation experiments cells were incubated for 20 min with $\mathrm{H}_{2} \mathrm{O}_{2}$ followed by a washing step, suspension in $\mathrm{S}$ buffer and incubation with C.EE for further 20 min. Controls were included by replacing C.EE by the same volume of the solvent (ethanol) and/or $\mathrm{H}_{2} \mathrm{O}_{2}$ by the same volume of $\mathrm{S}$ buffer.

\section{Comet assay}

The yeast comet assay was performed as described before. ${ }^{15}$ Briefly, cells from exponentially growing cultures were harvested by centrifugation at $18000 \times g$, for 2 min at $4{ }^{\circ} \mathrm{C}$, washed twice with ice-cold deionized $\mathrm{H}_{2} \mathrm{O}$, suspended in $\mathrm{S}$ buffer containing $2 \mathrm{mg} \mathrm{mL}^{-1}$ zymolyase (20000 $\mathrm{U} \mathrm{g}^{-1}$; ImmunO ${ }^{\mathrm{TM}}-20 \mathrm{~T}$ ) and $50 \mathrm{mM} \beta$-mercaptoethanol and incubated at $30^{\circ} \mathrm{C}, 200 \mathrm{rpm}$ for $40 \mathrm{~min}$, in order to obtain spheroplasts. After washing with $\mathrm{S}$ buffer, spheroplasts were suspended in S buffer containing 10 $\mathrm{mM} \mathrm{H}_{2} \mathrm{O}_{2}$, incubated for $20 \mathrm{~min}$ at $4{ }^{\circ} \mathrm{C}$ and subsequently washed with $\mathrm{S}$ buffer. Spheroplasts were embedded in $1.5 \%$ low melting agarose (w/v in $\mathrm{S}$ buffer) at $35{ }^{\circ} \mathrm{C}$, spread onto glass slides previously layered with $0.5 \%(\mathrm{w} / \mathrm{v})$ normal melting agarose, covered with a cover slip and incubated on ice in order to solidify the agarose. The cover slips were then removed and the unwinding of DNA and protein denaturation were made with ice-cold lysing buffer ( $30 \mathrm{mM} \mathrm{NaOH}, 1 \mathrm{M} \mathrm{NaCl}, 50 \mathrm{mM}$ ethylenediamine tetraacetic acid (EDTA), $10 \mathrm{mM}$ Tris-HCl, $0.05 \%(\mathrm{w} / \mathrm{v})$ lauroylsarcosine, $\mathrm{pH} 10)$ for $20 \mathrm{~min}$. Samples were subsequently stabilized in ice-cold electrophoresis buffer (30 $\mathrm{mM} \mathrm{NaOH}, 10 \mathrm{mM}$ EDTA, $10 \mathrm{mM}$ Tris-HCl, pH 10) for $20 \mathrm{~min}$. Glass slides were placed in an electrophoresis chamber and samples were exposed to $0.7 \mathrm{~V} \mathrm{~cm}^{-1}$ for $10 \mathrm{~min}$, at $4{ }^{\circ} \mathrm{C}$, to allow unwound DNA to move out of the nucleoids. The gels were neutralized with $10 \mathrm{mM}$ Tris-HCl buffer, $\mathrm{pH}$ 7.4, for $10 \mathrm{~min}$ at 4 ${ }^{\circ} \mathrm{C}$, samples were fixed, firstly in $76 \%(\mathrm{v} / \mathrm{v})$ ethanol and then in 96\% (v/v) ethanol, both for $10 \mathrm{~min}$, and the slides were dried at room temperature. After staining with $10 \mu \mathrm{L}$ of GelRed ${ }^{\mathrm{TM}}$ (diluted 3300 fold from the stock solution; Biotium) comets were visualized by fluorescence microscopy (Leica DMB 5000 with a P\&B, Leica, DFC 350FX digital camera) and tail length was measured from at least 20 comets per treatment with the CometScore software. Pre-, co- or post-incubation with C.EE were performed in the spheroplasts suspension as described for viability assays, before embedding in low melting agarose. Controls were also prepared as described in the same experimental procedure.

\section{Flow cytometry}

Cells from exponentially growing cultures were harvested as above, washed twice with the same volume of ice-cold PBS (137 $\mathrm{mM} \mathrm{NaCl}, 2.7 \mathrm{mM} \mathrm{KCl}, 4.3 \mathrm{mM} \mathrm{Na}_{2} \mathrm{HPO}_{4}, 1.47 \mathrm{mM} \mathrm{KH}_{2} \mathrm{PO}_{4}, \mathrm{pH}$ 7.4), diluted to an $\mathrm{OD}_{600}$ of 0.02 and $500 \mu \mathrm{L}$ were collected for measurement of autofluorescence. Cells were loaded with 50 $\mu \mathrm{M}$ dichlorofluorescein diacetate $\left(\mathrm{H}_{2} \mathrm{DCFDA}\right)$ by incubation at $30{ }^{\circ} \mathrm{C}, 200 \mathrm{rpm}$, during $1 \mathrm{~h}$ in the dark, after which they were washed twice with the same volume of ice-cold PBS. In coincubation experiments, aliquots of $1 \mathrm{~mL}$ were mixed with C.EE and $10 \mathrm{mM} \mathrm{H}_{2} \mathrm{O}_{2}$, for $20 \mathrm{~min}$, at $30^{\circ} \mathrm{C}, 200 \mathrm{rpm}$, in the dark. In pre- and post-incubation experiments cells were incubated, respectively, with the extract and subsequently with $\mathrm{H}_{2} \mathrm{O}_{2}$ or with $\mathrm{H}_{2} \mathrm{O}_{2}$ and subsequently with C.EE. Washing steps were included between each incubation step, as described above. 
Approximately twenty thousand cells of each sample were analysed by flow cytometry in an Epics ${ }^{\circledR}$ XLTM cytometer (Beckman Coulter) equipped with an argon-ion laser emitting a $488 \mathrm{~nm}$ beam at $15 \mathrm{~mW}$. Green fluorescence was collected through a 488 $\mathrm{nm}$ blocking filter, a $550 \mathrm{~nm}$ long-pass dichroic and a $225 \mathrm{~nm}$ band-pass filter. Data were analysed and histograms were made with the Flowing Software. Controls were included by replacing C.EE by the same volume of ethanol and $\mathrm{H}_{2} \mathrm{O}_{2}$ by PBS.

\section{Chemical analysis of C.EE}

Quantification of total polyphenols. The content in total polyphenols of the extract was determined by the Folin-Ciocalteu colorimetric method, ${ }^{16}$ with some modifications. Three hundred milligrams of C.EE solution $\left(0.5 \mathrm{mg} \mathrm{g}^{-1}\right.$ final concentration) were mixed with $2.0 \mathrm{~g}$ deionized $\mathrm{H}_{2} \mathrm{O}, 200 \mathrm{mg}$ Folin-Ciocalteu reagent (Panreac, Barcelona, Spain), $2.0 \mathrm{~g}$ of $10 \%(\mathrm{w} / \mathrm{v}) \mathrm{Na}_{2} \mathrm{CO}_{3}$, and deionized $\mathrm{H}_{2} \mathrm{O}$ to complete $10.0 \mathrm{~g}$ final mass of the mixture. The reducing power of the polyphenols in the mixture was evaluated using the $\mathrm{OD}_{760}$ measured after $1 \mathrm{~h}$ incubation at room temperature. C.EE polyphenol content was calculated using gallic acid as standard and results were expressed as milligrams of gallic acid equivalents per gram of C.EE (mg GAE per g).

Quantification of flavonoids. Total flavonoid content in the extract was determined using a method described by Woisky and Salatino. ${ }^{17}$ Five hundred milligrams of $2 \%(\mathrm{w} / \mathrm{v}) \mathrm{AlCl}_{3} \cdot 6 \mathrm{H}_{2} \mathrm{O}$ were added to $300 \mathrm{mg}$ of C.EE and ethanol was used to complete $10.0 \mathrm{~g}$ of mixture final mass. After $30 \mathrm{~min}$ incubation at room temperature, the $\mathrm{OD}_{420}$ of the mixture was measured and flavonoids content was calculated by comparison with the standard quercetin (1.2 $\mathrm{mg} \mathrm{g}^{-1}$ ) and expressed as milligrams of quercetin equivalents per gram of C.EE ( $\mathrm{mg}$ QE per $\mathrm{g}$ ).

LC-MS analysis. One hundred milligrams of C.EE were dissolved with $1 \mathrm{~mL}$ of $80 \%$ ethanol at $70{ }^{\circ} \mathrm{C}$ and filtered through a $0.22 \mu \mathrm{m}$ nylon filter prior to injection. Standards for gallic acid, protocatechuic acid, chlorogenic acid, vanillic acid, caffeic acid, syringic acid, ferulic acid, $o$-coumaric acid, apigenin, and kaempferol were acquired from Sigma-Aldrich Co. LLC. Luteolin and gentisic acid standards were acquired from Extrasynthese, France. The chromatographic system consisted of an Agilent 1200 series equipped with a triple quadrupole mass spectrometer Agilent 6400. A Sorbax SB-C18 $(50 \mathrm{~mm} \times 4.6 \mathrm{~mm}$ i.d. $\times 1.8 \mu \mathrm{m}$ particle diameter - Agilent Technologies) column was used for the separation at a flow rate of $0.7 \mathrm{~mL} \mathrm{~min}^{-1}$, at 30 ${ }^{\circ} \mathrm{C}$. Elution was performed by means of a gradient of $0.1 \%$ formic acid (eluent A) and acetonitrile (eluent $\mathrm{B}$ ). The gradient was as follows: started at $10 \% \mathrm{~B}, 20 \% \mathrm{~B}$ at $10 \mathrm{~min}, 40 \% \mathrm{~B}$ at $40 \mathrm{~min}$, $60 \% \mathrm{~B}$ at $60 \mathrm{~min}, 90 \% \mathrm{~B}$ at $80 \mathrm{~min}$, at $81 \mathrm{~min}$ return to initial conditions and stabilization for $9 \mathrm{~min}$. Electrospray ionization (ESI) was performed with a nitrogen flow of $10 \mathrm{~L} \mathrm{~min}^{-1}$ at $300{ }^{\circ} \mathrm{C}$ and the MS detector was operated in MS2-Scan scan type in the range 80-1000 $\mathrm{Da}$, and negative mode was selected. The capillary voltage was set to $4.0 \mathrm{kV}$, the quadrupole temperatures 100 ${ }^{\circ} \mathrm{C}$, fragmentor energy was $145 \mathrm{~V}$, and cell accelerator voltage was $7 \mathrm{~V}$. Data were acquired and analysed using Masshunter Workstation Software (version B.04.00) Agilent Technologies.
For MS/MS confirmation the same equipment and chromatographic conditions were used. The MS detector was operated in product ion scan type, selecting the precursor ions and performing a scan of the fragments in the range 80-500 Da and negative mode was selected. The capillary voltage set to $4.0 \mathrm{kV}$, the quadrupole temperatures were $100{ }^{\circ} \mathrm{C}$, fragmentor energy was $135 \mathrm{~V}$, cell accelerator voltage was $7 \mathrm{~V}$ and collision energy was $15 \mathrm{~V}$. Compounds were identified based on standards retention times and by comparison of the ESI-MS/MS data with the MS/MS data published in the literature.

\section{Statistical analysis}

All experiments were done in triplicate and the results are presented as mean \pm standard deviation (SD). For the comet assay, the mean was obtained from the mean of three independent experiments. One-way analysis of variance (1-way ANOVA) was used to evaluate treatment effects and Tukey's test was used to perform comparisons between each treatment with the respective control. Asterisks (or $\S \S$ ) indicate statistically significant differences: * means $0.01<p \leq 0.05, * *$ means 0.001 $<p \leq 0.01$, and $* * *$ means $p \leq 0.001$.

\section{Results \& discussion}

\section{C.EE polyphenolic content and chemical profile}

Polyphenols constitute an important group of biologically active compounds abundant in propolis samples. Particularly, the flavonoids have been associated with the antioxidant properties exhibited by plant and plant-based products, such as propolis, ${ }^{5}$ but also some phenolic acids and their esters possess antioxidant activity. ${ }^{18}$ Hence, to assess C.EE bioactivity potential, an initial quantitative characterization involved the determination of total polyphenols and total flavonoids contents (Table 1).

Total phenols of C.EE were in the range reported in the literature (120-443 mg GAE per $\mathrm{g}$ extract), ${ }^{19}$ but in the lower third of the rank. The values are similar to those found for Portuguese samples from the centre of Portugal ${ }^{20}$ but are also comparable to those of very distant places, such as India; ${ }^{5}$ Anhui, China; ${ }^{21}$ and to the red propolis from Brazil. ${ }^{22}$ Although still in the range for total flavonoids (25-140 mg QE per $\mathrm{g}$ extract) also low levels were obtained for C.EE (Table 1). Again, this content is similar to that of some Portuguese samples from Alentejo, ${ }^{20}$ but also to red propolis from $\mathrm{Cuba}^{19}$ and to some samples collected in Anhui, China. ${ }^{21}$

The sample was further characterized qualitatively by LC-MS analysis (Table 2 and ESI Fig. $1 \dagger$ ). Compounds were identified using standards, or by comparison of MS/MS fragmentation and

Table 1 Chemical characterization of Côa propolis ethanol extract (C.EE). The content of total polyphenols and total flavonoids was expressed, respectively, in equivalents of gallic acid (mg GAE) and in equivalents of quercetin ( $m g \mathrm{QE}$ ) per gram of propolis extract

\begin{tabular}{lll}
\hline Sample & $\begin{array}{l}\text { Total polyphenols } \\
(\mathrm{mg} \text { GAE per g) }\end{array}$ & $\begin{array}{l}\text { Total flavonoids } \\
\text { (mg QE per g) }\end{array}$ \\
\hline C.EE & $160.40 \pm 16.56$ & $30.21 \pm 0.52$
\end{tabular}


Table 2 Identification of phenolic compounds from Côa propolis extract (C.EE), by LC-MS/MS

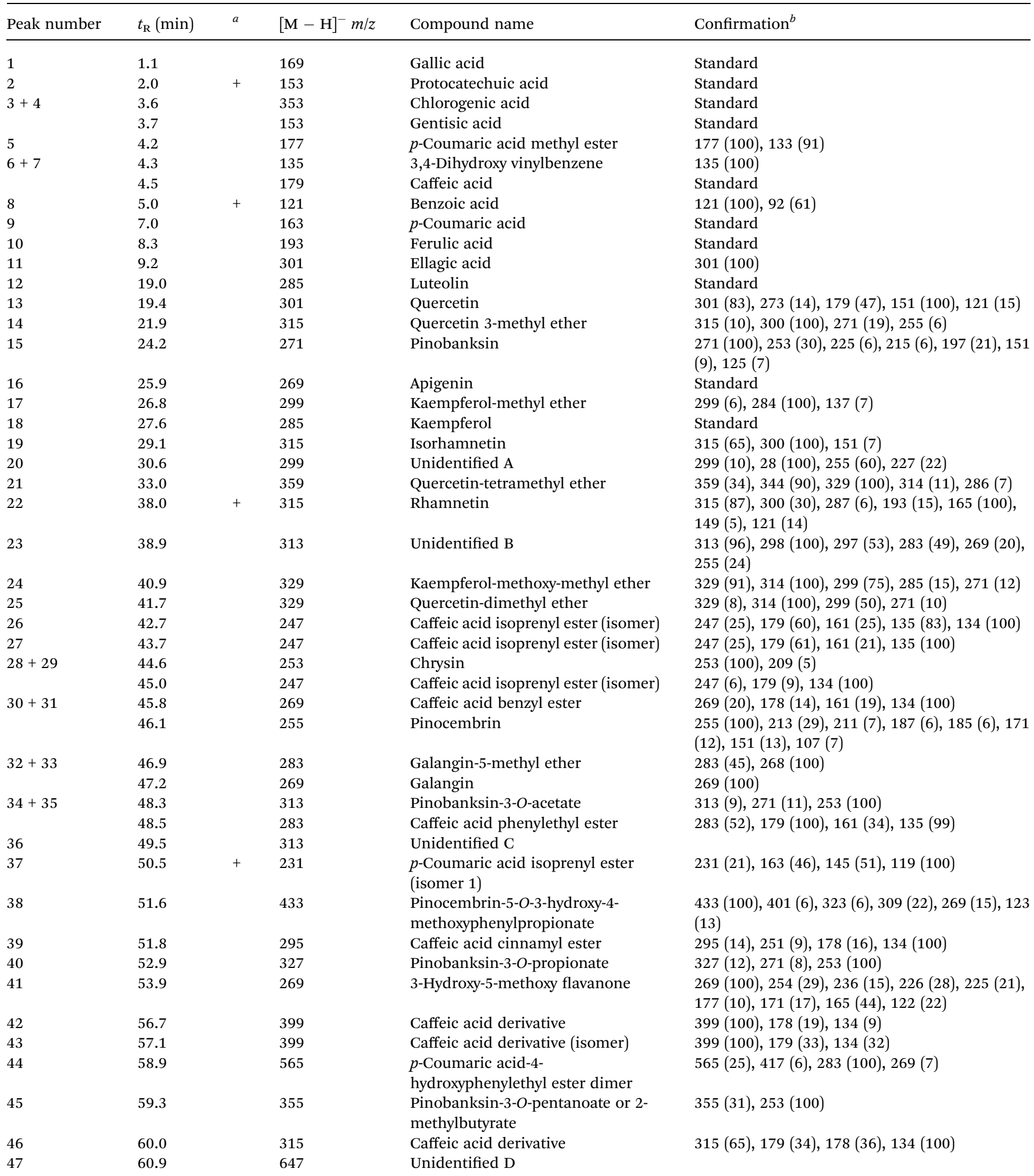

${ }^{a}+$ indicates that TIC peak is not pure. ${ }^{b}$ Standard - for compounds identified with standards, or $m / z$ (abundance percent) - for compounds confirmed by comparison of MS/MS fragmentation with bibliography. See chromatogram in ESI Fig. 1.

relative retention times with those described in the literature. ${ }^{23-25}$ Similarly to what has been described for other propolis samples, C.EE is mostly constituted by flavonoids, phenolic acids and their esters, being flavones, flavonols and flavanones the main flavonoid groups as previously reported. ${ }^{26}$ In this sample 43 phenolic compounds were identified: benzoic and hydroxybenzoic acids, 
caffeic acid esters (caffeic acid isoprenyl esters, caffeic acid benzyl ester, caffeic acid cinnamyl ester and caffeic acid phenethyl ester - CAPE) and derivatives, $p$-coumaric acid and esters ( $p$-coumaric methyl ester, $p$-coumaric isoprenyl ester and $p$-coumaric acid-4hydroxyphenylethyl ester dimer), flavonols (quercetin, kaempferol, galangin), flavones (luteolin, apigenin, chrysin), flavanones (pinocembrin) and dihydroflavonols (pinobanksin) (Table 2). With the exception of acacetin, all most important flavonoids reported for propolis, apigenin, galangin, chrysin, quercetin, CAPE, luteolin, pinocembrin, pinobanksin and kaempferol, ${ }^{26}$ are present in this sample. It is also noteworthy that this extract is particularly rich in methoxylated flavonoids (quercetin-3-methyl ether, quercetin-dimethyl ether, quercetin-tetramethyl ether, rhamnetin, isorhamnetin, kaempferol-methoxy-methyl ether, galangin-5-methyl ether, pinocembrin-5-O-3-hydroxy-4methoxyphenyl propionate and 3-hydroxy-5-methoxy flavanone) and in pinobanksin derivatives (pinobanksin-3-O-acetate, pinobanksin-3-O-acetate, pinobanksin-3-O-propionate, pinobanksin3-O-pentanoate). Most of these compounds are generally present in the common temperate propolis type, ${ }^{24}$ which is the most common in Europe, China and Argentina, ${ }^{25}$ indicating that, as expected, the C.EE sample fits into this propolis type. In particular, high relative amounts of chrysin, pinocembrin and galangin denote that poplar is an important source of raw material. ${ }^{19}$ However, the phenolic composition of this sample displays some distinct features like the presence of uncommon phenolic acids, such as 3,4-dihidroxy vinylbenzene, and the rare non-flavonoid phenolic ellagic acid, reported recently for Portuguese propolis. ${ }^{24}$

Despite the low total flavonoid content (Table 1), that may partially be explained by an underestimation of flavanones and dihydroflavonols by the use of the aluminium chloride-ethanol method, the results obtained from chemical characterization, revealing flavonoid diversity and in high relative abundance, suggest that C.EE may exhibit some of the widely reported propolis biological activities, namely the antioxidant. Indeed, flavonoids (such as pinobanksin, kaempferol, pinocembrin and galangin) and phenolic acids (caffeic acid and CAPE) have been the classes of phenolic substances most extensively reported to have antioxidant activity. On the other hand, a close correlation between antioxidant potential and the total content in flavonoids is not always observed (see the reviews ${ }^{\mathbf{1 9}, 21}$ ), the presence of specific compounds in propolis composition being more indicative of its bioactivity profile.

Relevant bioactivities have been described for most of these compounds, such as anti-proliferative, anti-tumor, antimicrobial and antioxidant, but also pro-oxidant effects were reported for some flavonoids, depending on the redox state of the environment. ${ }^{27}$ For this a set of assays were performed to study the antioxidant properties of C.EE at the cell and DNA levels using the yeast model and different technical approaches.

\section{Effects of C.EE on cell viability under oxidative stress conditions}

To test the hypothesis that C.EE is capable of protecting cells against oxidative stress, yeast cells were pre-incubated with C.EE and their viability was assessed, as CFUs, in the presence of $\mathrm{H}_{2} \mathrm{O}_{2}$ for $90 \mathrm{~min}$. Also, co-incubation and post-incubation experiments were performed to investigate the antioxidant activity of the extract in the presence of the stressor agent and its participation in cell recovery from oxidative damage, respectively.

When cells were pre-incubated with C.EE at $100 \mu \mathrm{g} \mathrm{mL}$ (Fig. 1A) and $300 \mu \mathrm{g} \mathrm{mL} \mathrm{m}^{-1}$ (Fig. 1B), viability loss was reduced when compared to control cells (pre-treated with ethanol) ( $p=$ 0.0018 and $p=0.0011$ after $60 \mathrm{~min}$ incubation, respectively), during the $90 \mathrm{~min}$ of exposure to $5 \mathrm{mM} \mathrm{H}_{2} \mathrm{O}_{2}$. Cells treated only with $\mathrm{S}$ buffer or pre-treated with ethanol or C.EE, and afterwards with water, displayed a nearly constant viability throughout the experiment (Fig. 1A and B). These results suggest that C.EE triggers a protection mechanism in yeast cells that allows increased resistance against oxidative stress.

To investigate a direct effect on the oxidant agent $\left(\mathrm{H}_{2} \mathrm{O}_{2}\right)$ and/or early antioxidant effects of C.EE we have determined the viability in co-incubation experiments. As depicted in Fig. 1D, $100 \mu \mathrm{g} \mathrm{mL}{ }^{-1}$ C.EE significantly decreased the rate of viability loss ( $p=0.0097$ after $60 \mathrm{~min}$ incubation) of cells exposed to 5 $\mathrm{mM} \mathrm{H}_{2} \mathrm{O}_{2}$, while $25 \mu \mathrm{g} \mathrm{mL} \mathrm{md}^{-1}$ and $300 \mu \mathrm{g} \mathrm{mL} \mathrm{m}^{-1}$ C.EE had no significant effect (Fig. 1C and E, respectively). In addition, unlike cells treated with $2 \%$ ethanol or with $\mathrm{S}$ buffer, cells incubated with $100 \mu \mathrm{g} \mathrm{mL}{ }^{-1}$ C.EE $(p=0.0029)$ or $300 \mu \mathrm{g} \mathrm{mL} \mathrm{m}^{-1}$ C.EE $(p=0.005)$ displayed increased loss of viability (Fig. 1D and $\mathrm{E})$. The differences regarding pre-incubation experiments with the same concentrations of C.EE are consistent with the fact that while cells were in contact with C.EE for $20 \mathrm{~min}$ in preincubation experiments, in co-incubation experiments cells contacted with C.EE for $90 \mathrm{~min}$. Together these observations suggest that there is a range of concentrations where C.EE protects cells against oxidative stress and a concentration threshold above which C.EE has a toxic effect on yeast cells.

The hypothesis that propolis could also improve recovery of cells after oxidative shock was tested by performing postincubation experiments, which are based on a previous treatment with $\mathrm{H}_{2} \mathrm{O}_{2}$ for $20 \mathrm{~min}$, wash of the cells to remove the toxicant and a subsequent 20 min treatment with C.EE. As expected, considering the short term incubation, cells without any treatment or treated only with C.EE or $2 \%$ ethanol (solvent control) showed a nearly constant survival rate throughout the experiment (Fig. 1F-H). After treatment with $5 \mathrm{mM} \mathrm{H}_{2} \mathrm{O}_{2}$ for 20 min, when yeast cells were incubated with $2 \%$ ethanol or C.EE (see Fig. 1F-H after minute 20), the viability loss rate did not change significantly (Fig. $1 \mathrm{~F}$ and $\mathrm{G}$ ), except in the experiment with $300 \mu \mathrm{g} \mathrm{mL} \mathrm{mL}^{-1}$ C.EE, which promoted a reproducible although not statistically significant faster loss of viability when compared with the respective control (Fig. 1H). These results proved that C.EE could not improve recovery from oxidative stress but also that at the highest concentration tested $(300 \mu \mathrm{g}$ $\mathrm{mL}^{-1}$; Fig. 1H) C.EE increased the loss of viability. In fact, when comparing viability loss after $20 \mathrm{~min}$ in the presence of $300 \mu \mathrm{g}$ $\mathrm{mL}^{-1}$ C.EE in all experiments (time-point $40 \mathrm{~min}$ in Fig. $1 \mathrm{H}$ ), in the post-incubation experiment the C.EE effect was higher (Fig. 1B, E and H). These results may be explained by an exacerbated pro-oxidant effect of C.EE in cells that were exposed previously to oxidative challenge by $\mathrm{H}_{2} \mathrm{O}_{2}$ (Fig. 1H). It should 

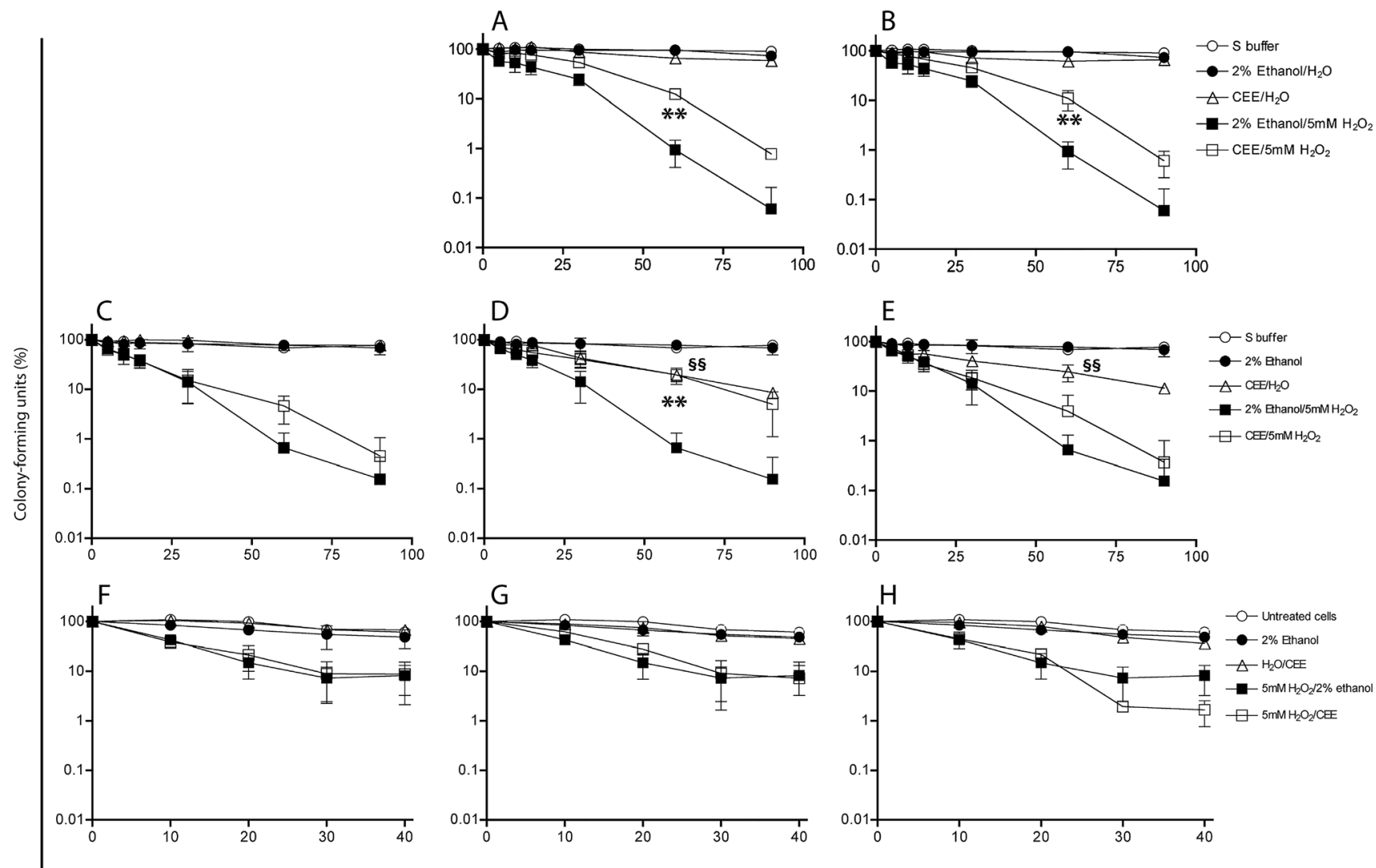

Time (min)

Fig. 1 Influence of pre-incubation ( $A$ and $B$ ), co-incubation ( $C, D$ and $E$ ) and post-incubation ( $F, G$ and $H$ ) with $C$.EE on the kinetics of loss of viability of $S$. cerevisiae cells exposed to oxidative stress. Yeast cells were incubated with $C$.EE $\left(25 \mu \mathrm{g} \mathrm{mL}^{-1},(\mathrm{C}\right.$ and $\mathrm{F}) ; 100 \mu \mathrm{g} \mathrm{mL}{ }^{-1},(\mathrm{~A}, \mathrm{D}$ and $\mathrm{G})$; or $300 \mu \mathrm{g} \mathrm{mL}^{-1}, \mathrm{~B}, \mathrm{E}$ and $\mathrm{H}$ ) and with $5 \mathrm{mM} \mathrm{H}_{2} \mathrm{O}_{2}$ (see Experimental for details). At each time-point an aliquot was collected, diluted and spread on YPD plates. Colonies were counted after $48 \mathrm{~h}$ of incubation at $30{ }^{\circ} \mathrm{C}$ and viability was calculated as percentage, taking time 0 min as reference $\left(100 \%\right.$ viability). Data are the mean \pm SD of three independent experiments. ** means $0.001<p \leq 0.01$ between samples treated with $\mathrm{H}_{2} \mathrm{O}_{2}$ and samples treated with $\mathrm{H}_{2} \mathrm{O}_{2}$ and $\mathrm{C}$.EE (pre-incubation and co-incubation). $\S \S$ means $0.001<p \leq 0.01$ between C.EE-treated samples and those treated with the solvent of C.EE (pre-incubation).

not be excluded however non-oxidative mechanisms of C.EE triggering general stress response in yeast cells.

Tsai et al. ${ }^{13}$ proposed that flavonoids from propolis could be pro-oxidant and genotoxic by reaction with metal ions. Besides C.EE flavonoid total content being relatively low, it is also known that some flavonoids, like quercetin, are more prone to oxidation than others, especially at physiological $\mathrm{pH} .^{28}$ Therefore the composition must also be taken into account when analysing these properties and considering that quercetin is one of C.EE components (Table 2) it is tempting to explain the decrease of cell viability by a significant pro-oxidant activity of C.EE. This is also supported by post-incubation experiments with the highest concentration tested $\left(300 \mu \mathrm{g} \mathrm{mL}{ }^{-1}\right.$; Fig. $\left.1 \mathrm{H}\right)$, where the increased rate in viability loss with C.EE after a previous incubation period with $\mathrm{H}_{2} \mathrm{O}_{2}$ could be explained by further accumulation of oxidative damage in the cells. In studies also with propolis of Portuguese origin, cytotoxicity was observed in human tumour cell lines. Our results could help to explain such activity. In all cases however, a link between cytotoxicity and pro-oxidant activity was not reported, being the mechanism either not studied ${ }^{29,30}$ or associated with a disturbance of the glycolytic metabolism. ${ }^{31}$

Globally, the results suggest that C.EE can protect yeast cells against an induced oxidative stress, possibly by direct scavenging and reduction of free radicals and by improving adaptation of cells to stress. In addition C.EE can have cytotoxic effects at higher concentrations, especially in already compromised yeast cells by a previous exposure to oxidative stress.

\section{C.EE protects yeast cells from DNA damage induced by $\mathrm{H}_{2} \mathrm{O}_{2}$}

It is conceivable that at least some of the antioxidant effects reported for propolis ${ }^{5,32}$ have an impact in genomic DNA integrity under oxidative challenges by avoiding DNA damage. As the propolis sample herein studied also displayed antioxidant activity, it was decided to investigate its antigenotoxicity.

Yeast spheroplasts were pre-treated for 20 min with $25 \mu \mathrm{g}$ $\mathrm{mL}^{-1}, 100 \mu \mathrm{g} \mathrm{mL}^{-1}$ or $300 \mu \mathrm{g} \mathrm{mL} \mathrm{m}^{-1} \mathrm{C}$.EE in $\mathrm{S}$ buffer, to maintain osmotic protection, and then exposed to $10 \mathrm{mM} \mathrm{H}_{2} \mathrm{O}_{2}$. Exposure to $\mathrm{H}_{2} \mathrm{O}_{2}$, after pre-incubation with $2 \%$ ethanol (extract solvent), increased dramatically comet tail length (Fig. 2A) confirming 
that the $\mathrm{H}_{2} \mathrm{O}_{2}$ concentration used in the experiments was genotoxic. However, when yeast spheroplasts were pre-treated with C.EE before exposure to $\mathrm{H}_{2} \mathrm{O}_{2}$, a statistically significant decrease in comet tail length was observed even for the lowest concentration tested (Fig. 2A). This result indicates that C.EE has a potent antigenotoxic activity by protecting cells against oxidative-induced DNA damage and is consistent with the increase in yeast viability previously observed in the preincubation experiment (Fig. 1A and B).

Acknowledging the cytotoxic properties of C.EE, a possible explanation for its antigenotoxic effect is that a mild genotoxic effect of C.EE could trigger adaptation of cells against oxidative stress by $\mathrm{H}_{2} \mathrm{O}_{2}$. To investigate this hypothesis, spheroplasts were incubated with different C.EE concentrations and then with $\mathrm{S}$ buffer instead of $\mathrm{H}_{2} \mathrm{O}_{2}$. A statistically significant increase in comet tail length was observed only with $300 \mu \mathrm{g} \mathrm{mL}{ }^{-1}$ C.EE when compared with cells treated with $2 \%$ ethanol (Fig. 2B), indicating that C.EE has also genotoxic activity. DNA damage induced by $300 \mu \mathrm{g} \mathrm{mL} \mathrm{m}^{-1}$ C.EE alone (Fig. 2B) is similar to that found in C.EE pre-treated cells when subjected to $\mathrm{H}_{2} \mathrm{O}_{2}$ (Fig. 2A), suggesting that the potential for genoprotection is constrained by its genotoxicity. These results seem to support the hypothesis that C.EE may exert its antioxidant/antigenotoxic activity through a mild geno-insult enabling cells to adapt to subsequent genotoxic oxidative stresses like that induced by $\mathrm{H}_{2} \mathrm{O}_{2}$.
Similarly to what was done in the cell viability assays, coincubation experiments using yeast spheroplasts were performed to investigate if C.EE can protect DNA from damage under oxidative stress conditions, presumably by direct ROS detoxification. In this experiment spheroplasts were incubated with C.EE and $10 \mathrm{mM} \mathrm{H}_{2} \mathrm{O}_{2}$ for $20 \mathrm{~min}$, after which DNA damage was analysed as before. As observed in pre-incubation experiments, $\mathrm{H}_{2} \mathrm{O}_{2}$ increased dramatically comet tail length (Fig. 2C) and when yeast spheroplasts were treated with $\mathrm{H}_{2} \mathrm{O}_{2}$ and C.EE simultaneously, a significant decrease of DNA damage was observed (Fig. 2C). Hence these results suggest that reducing/scavenging activities by some C.EE compounds may be protecting cells against $\mathrm{H}_{2} \mathrm{O}_{2}$-induced oxidative DNA damage. Genotoxicity of C.EE was also investigated after incubation of spheroplasts with propolis extract without $\mathrm{H}_{2} \mathrm{O}_{2}$ and omitting the subsequent step of incubation of $20 \mathrm{~min}$ that allows DNA damage repair. A significant increase in tail length was observed for all concentrations tested (with $\mathrm{S}$ buffer) when compared with the ethanol control (Fig. 2D), indicating that C.EE acted as a genotoxic agent to $S$. cerevisiae cells. These results together with the decrease of viability observed for 100 $\mu \mathrm{g} \mathrm{mL} \mathrm{m}^{-1}$ and $300 \mu \mathrm{g} \mathrm{mL}{ }^{-1}$ C.EE (Fig. 1D and E) indicate that DNA damage is possibly involved in C.EE-induced loss of cell viability. In fact, propolis flavonoids, as effective scavengers of free radicals and other reactive species in vitro, may explain a decrease in oxidative DNA damage in vivo. ${ }^{33}$ So, antigenotoxicity and genotoxicity were observed in both pre-
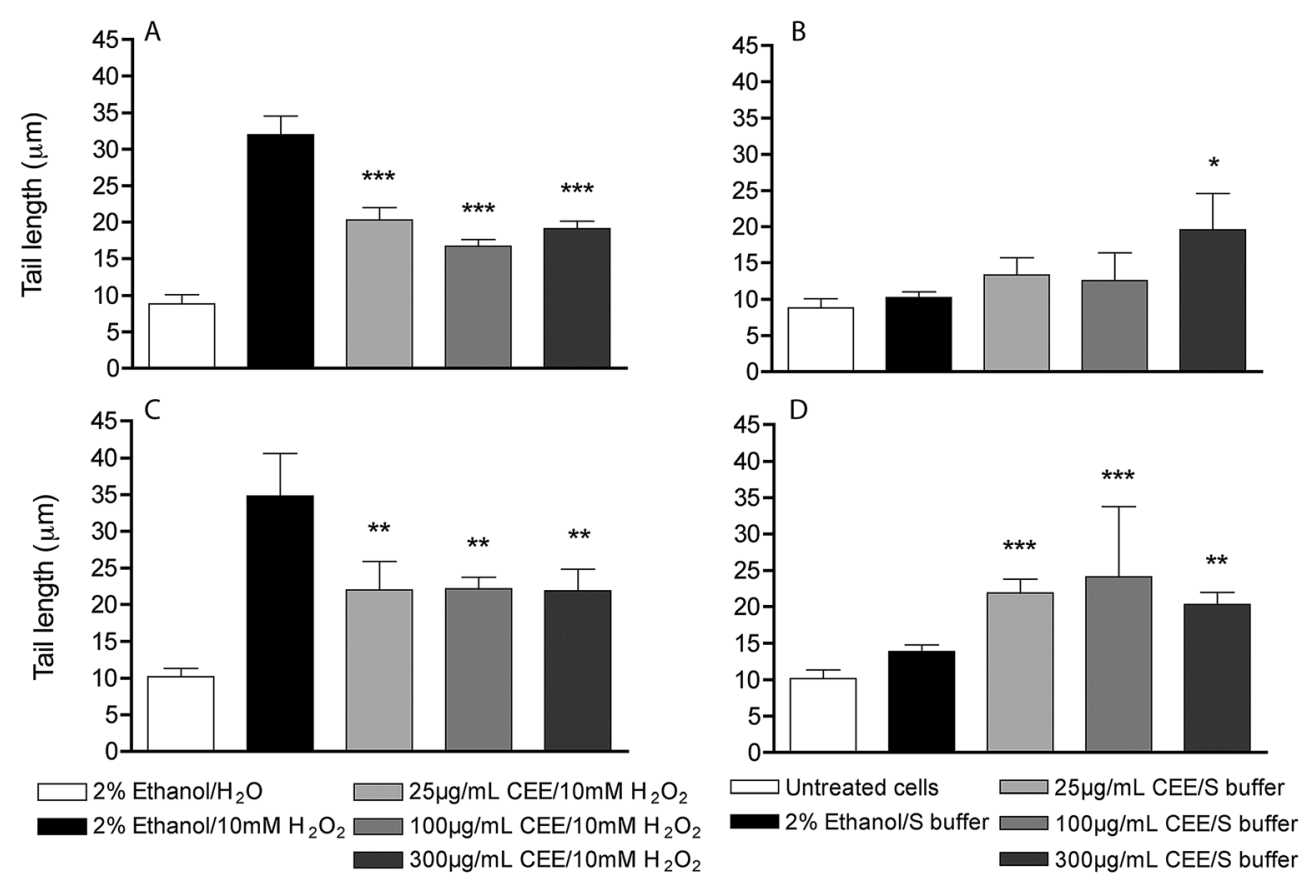

Fig. 2 Antigenotoxicity of C.EE in S. cerevisiae cells exposed to oxidative stress ( $A$ and $C$ ) and genotoxicity of C.EE in S. cerevisiae cells (B and D). Yeast spheroplasts were pre-treated with C.EE $\left(25 \mu \mathrm{g} \mathrm{mL}^{-1}, 100 \mu \mathrm{g} \mathrm{mL}^{-1}\right.$ or $\left.300 \mu \mathrm{g} \mathrm{mL}^{-1}\right)$ for 20 min, washed with $\mathrm{S}$ buffer and incubated with 10 $\mathrm{mM} \mathrm{H}_{2} \mathrm{O}_{2}$ (A) or S buffer (B) for further $20 \mathrm{~min}$. In co-incubation experiments, spheroplasts were incubated with C.EE $\left(25 \mu \mathrm{g} \mathrm{mL} \mathrm{L}^{-1}, 100 \mu \mathrm{g} \mathrm{mL} \mathrm{m}^{-1}\right.$ or $300 \mu \mathrm{g} \mathrm{mL}{ }^{-1}$ ) and $10 \mathrm{mM} \mathrm{H}_{2} \mathrm{O}_{2}$ for $20 \mathrm{~min}$ (C) or with C.EE and S buffer for 20 min, which was used instead of $\mathrm{H}_{2} \mathrm{O}_{2}$ (D). DNA damage was analysed with the yeast comet assay (see Experimental section). Controls included untreated cells as well as cells treated with the solvent of $C$. EE (ethanol; $2 \%$ final concentration as in the assays with C.EE). Mean \pm SD values are from three independent experiments (* represents $0.01<p \leq$ $0.05, * *$ represents $0.001<p \leq 0.01$ and $* * * p \leq 0.001)$. 

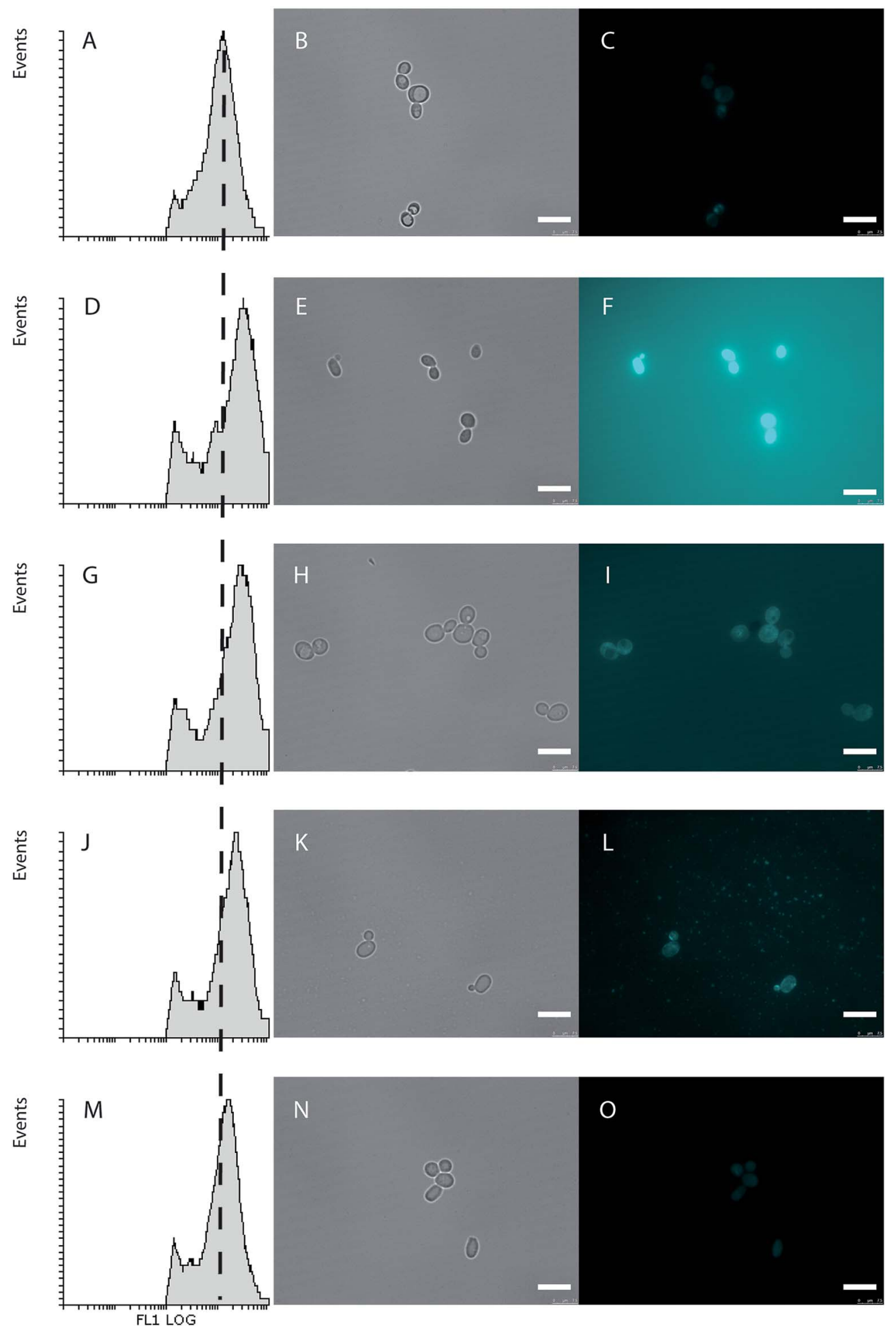

Fig. 3 Intracellular oxidation of $\mathrm{S}$. cerevisiae cells exposed to $\mathrm{H}_{2} \mathrm{O}_{2}$ is decreased in the presence of C.EE. Cells were loaded with $\mathrm{H}_{2}$ DCFDA and treated simultaneously with $2 \%$ ethanol (A-C), $10 \mathrm{mM} \mathrm{H}_{2} \mathrm{O}_{2}$ (D-F) or with $10 \mathrm{mM} \mathrm{H}_{2} \mathrm{O}_{2}$ and C.EE ((G-l) $25 \mu \mathrm{g} \mathrm{mL} \mathrm{m}^{-1}$; (J-L) $100 \mu \mathrm{g} \mathrm{mL}-1$; (M-O) 300 $\mu \mathrm{g} \mathrm{mL}^{-1}$ ) simultaneously for $20 \mathrm{~min}$ and analysed for fluorescence by flow cytometry ( $\mathrm{A}, \mathrm{D}, \mathrm{G}, \mathrm{J}$ and $\left.\mathrm{M}\right)$, bright-field microscopy (B, E, $H, K$ and $N$ ) and fluorescence microscopy (C, F, I, L and O). Data are from a representative experiment from three independent experiments. Bar $=10 \mu \mathrm{m}$.

incubation and co-incubation experiments, which strongly supports a dual activity of C.EE propolis regarding DNA integrity. A similar behaviour regarding genotoxic and antigenotoxic dual role of propolis has been previously reported by Tavares and co-workers ${ }^{34}$ for a Brazilian propolis sample. However, in that study, the antigenotoxic activity was observed against the DNA intercalating chemotherapeutic drug doxorubicin. 

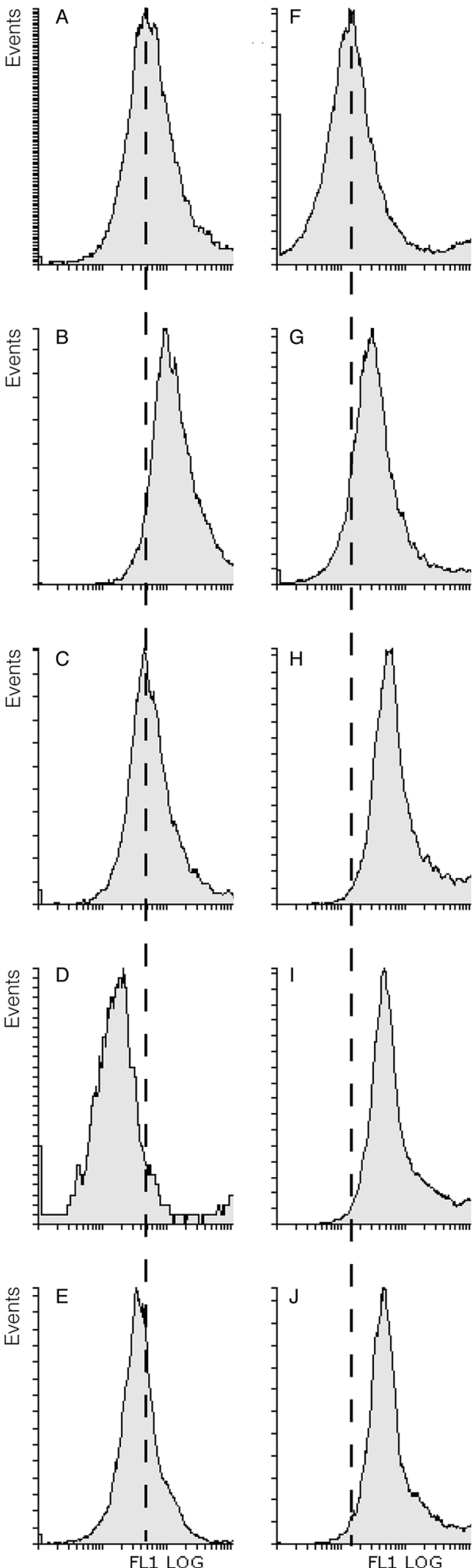

Fig. 4 Intracellular oxidation of $S$. cerevisiae cells pre-incubated with C.EE and exposed to $\mathrm{H}_{2} \mathrm{O}_{2}$ is decreased while post-incubation with C.EE aggravates intracellular oxidation. Cells were loaded with $\mathrm{H}_{2}$ DCFDA, incubated with $2 \%$ ethanol (A and B), or C.EE ((C) $25 \mu \mathrm{g}$ $\mathrm{mL}^{-1}$; (D) $100 \mu \mathrm{g} \mathrm{mL}^{-1}$; (E) $300 \mu \mathrm{g} \mathrm{mL}^{-1}$ ), washed and incubated with $\mathrm{H}_{2} \mathrm{O}(\mathrm{A})$ or $10 \mathrm{mM} \mathrm{H}_{2} \mathrm{O}_{2}$ (B, C, D and E). Alternatively, H2DCFDA-loaded cells were incubated with $\mathrm{H}_{2} \mathrm{O}(\mathrm{F})$, or $10 \mathrm{mM} \mathrm{H}_{2} \mathrm{O}_{2}(\mathrm{G}, \mathrm{H}, \mathrm{I}$ and J),
It is interesting to note that lower concentrations of C.EE ( 25 $\mu \mathrm{g} \mathrm{mL}^{-1}$ and $100 \mu \mathrm{g} \mathrm{mL}^{-1}$ ) displayed genotoxicity only in coincubation experiments where damage was analysed immediately after incubation unlike the pre-incubation experiments, which included an additional incubation with $\mathrm{S}$ buffer (Fig. 2B and D). Repair of DNA damage during this incubation may be the reason explaining the difference observed in both experiments. In fact, DNA repair activity during incubation of yeast cells with S buffer, as has been reported before, ${ }^{15}$ could eliminate DNA injuries caused by C.EE in pre-incubation up to a maximum C.EE concentration, after which the amount of damage caused being presumably in excess to the repairing capacity of cells.

Genotoxicity detected in the alkaline comet assay (Fig. 2B and D) argues also in favour of a pro-oxidant activity. Longer comet tails are caused by single strand and double strand breaks, the former being one of the DNA lesions typically detected in the alkaline version of the comet assay as a result of oxidative DNA damage. ${ }^{35}$ Nevertheless, the possibility of a different non-oxidative stressing activity by propolis cannot be disregarded since these complex mixtures might contain genotoxic compounds that could lead to similar results as those presented in this work. The finding that propolis extract can enhance the antitumor activity of irinotecan, which induces DNA double-strand breaks by a non-oxidative mechanism ${ }^{36}$ provides support to this idea. Also, many propolis compounds, namely most of those found in C.EE, have been reported to have anti-proliferative, anti-tumour and anticancer effects. For instance, caffeic acid, CAPE, quercetin, apigenin, kaempferol, chrysin and galangin all exhibit antitumor activity (for a thorough review $\mathrm{se}^{33}$ ). Quercetin 3-methyl ether, a methoxylated flavonoid, has potent anticancer-promoting activity by inducing cell cycle G2-M phase accumulation. ${ }^{37}$ Chrysin inhibits DNA synthesis by G1 cell cycle arrest in C6 glioma cells. ${ }^{38}$ Even at low concentrations ellagic acid interacts synergistically with quercetin enhancing the anticarcinogenic activity of the individual counterparts. ${ }^{39}$ Pro-oxidant activity of C.EE may be responsible for its toxicity, but could also have an indirect role in protection due to induction of antioxidant defences and xenobiotic metabolizing enzymes by the imposition of a mild oxidative stress, which may contribute to a more effective cytoprotection. ${ }^{40}$

\section{C.EE decreases intracellular oxidation in pre-incubation and co-incubation experiments}

To investigate if the antioxidant effect of C.EE in the presence of $\mathrm{H}_{2} \mathrm{O}_{2}$ is mediated by a decrease in intracellular oxidation level, cells under co-incubation conditions were analysed using flow cytometry and $\mathrm{H}_{2}$ DCFDA as the fluorescent redox-sensitive probe. This lipophilic compound permeates the cells and is deacetylated to dichlorofluorescein by intracellular esterases.

washed and incubated with $2 \%$ ethanol ( $F$ and $G$ ) or C.EE $((\mathrm{H}) 25 \mu \mathrm{g}$ $\mathrm{mL}^{-1}$; (I) $100 \mu \mathrm{g} \mathrm{mL}^{-1}$; (J) $300 \mu \mathrm{g} \mathrm{mL}^{-1}$ ). All cells were analysed for fluorescence by flow cytometry. Data are from a representative experiment from three independent experiments. 
The deacetylated form is hydrophilic and becomes trapped inside the cells. In the presence of oxidants, it oxidizes and fluoresces with a maximum of excitation at $485 \mathrm{~nm}$ and of emission at $530 \mathrm{~nm}$. As depicted in Fig. 3 the presence of $\mathrm{H}_{2} \mathrm{O}_{2}$ induced a significant peak displacement towards higher levels of fluorescence (Fig. 3A and D), revealing an increase in intracellular oxidation. Treatment with C.EE decreased this intracellular fluorescence in a dose-dependent manner (Fig. 3G, J and $\mathrm{M}$ ). Inspection of cells by bright-field (Fig. 3B, E, H, K and N) and fluorescence (Fig. 3C, F, I, L and O) microscopy confirmed both, the intracellular origin of fluorescence and the dose-dependent effect on fluorescence decrease by the extract.

The same approach was used to investigate the antioxidant activity of C.EE in pre-incubation and post-incubation conditions, similarly to experiments of viability and the comet assay (Fig. 4). The antioxidant activity of the extract was still present in pre-incubation experiments in all concentrations tested (Fig. 4C-E). Interestingly, prior incubation of cells with the extract completely abolished the oxidative effect of $\mathrm{H}_{2} \mathrm{O}_{2}$ as the intracellular fluorescence of dichlorofluorescein was similar (25 $\mu \mathrm{g} \mathrm{mL}^{-1}$ C.EE; Fig. 4C) or lower (100 and $300 \mu \mathrm{g} \mathrm{mL}{ }^{-1}$ C.EE; Fig. 4D and E, respectively) when compared to the negative control. These results correlate with the viability assays with pre-incubation of C.EE, where a decrease in the rate of loss of viability was observed (Fig. 1A and B) when compared with cells pre-incubated with the solvent ( $2 \%$ ethanol). As suggested by the loss of viability in co-incubation experiments in cells incubated only with C.EE (Fig. 1D and E), a pro-oxidant activity of C.EE is compatible with a mechanism of induction of the cellular response against oxidative stress. In addition, preincubation with $300 \mu \mathrm{g} \mathrm{mL} \mathrm{mL}^{-1} \mathrm{C}$.EE did not decrease further the intracellular oxidation as it should be anticipated in a dosedependent activity (Fig. 4E), suggesting that at this concentration the pro-oxidant activity might be too strong to yield an increase in the protective effect, which correlates with the absence of increase in viability protection when the concentrations of 100 and $300 \mu \mathrm{g} \mathrm{mL}^{-1}$ are compared (Fig. 1A and B). In post-incubation experiments an increase in intracellular oxidation was observed for all concentrations tested (Fig. 4H-J), which is in line with a pro-oxidant activity of C.EE.

The dose-dependent intracellular antioxidant activity in coincubation experiments is in accordance with the observed protective effect in cell viability (Fig. 1) and the antigenotoxic activity upon oxidative shock (Fig. 2) and with the view of some compounds acting directly in quenching oxidative species. ${ }^{2}$ The evaluation of propolis antioxidant potential is generally performed by in vitro assays (e.g. DPPH, ABTS). ${ }^{41-43}$ Here, the antioxidant effects of C.EE were evaluated in vivo using an eukaryotic cell model, as others did before, ${ }^{44,45}$ which is of higher significance when considering applications in human cells and tissues or in a whole-body physiological context. However, in our study the antioxidant activity was investigated in cells under highly challenging conditions by exogenously added $\mathrm{H}_{2} \mathrm{O}_{2}$, which highlights the antioxidant potency of this propolis extract.

\section{Conclusions}

Globally, these results fit in the so-called "Janus" effect, which is used to classify compounds or mixtures that have a dual effect, one positive and one negative. ${ }^{46}$ These dual and opposite effects of propolis have been also reported before by Tavares et al. ${ }^{34}$ for Brazilian green propolis, which also acts as antigenotoxic against the DNA intercalating chemotherapeutic drug doxorubicin at low concentration and as genotoxic at high concentration. Here we provide evidence that the Janus effect of propolis is also present when cells are challenged with an oxidationmediated DNA damaging agent such as $\mathrm{H}_{2} \mathrm{O}_{2}$ and that detection can be made with the alkaline version of the comet assay. In conclusion, depending of the dose, the studied propolis extract exhibits both genotoxic and antigenotoxic activities and acts as an intracellular antioxidant in cells challenged with $\mathrm{H}_{2} \mathrm{O}_{2}$. These conclusions highlight the need for careful formulation of propolis-based food and medical products and for biological monitoring of these products to avoid undesirable harming effects.

\section{Conflicts of interest}

The authors declare that there are no conflicts of interest.

\section{Acknowledgements}

The authors are thankful to Cristina Ribeiro (Department of Biology, University of Minho) for her collaboration in flow cytometry experiments and to Pedro Fernandes, from Mel do Abel, who kindly collected and provided the propolis sample for the study. This work is supported by national funds by FCT Portuguese Foundation for Science and Technology, under the projects UID/AGR/04033/2013 and POCI-01-0145-FEDER006958.

\section{Notes and references}

1 V. S. Bankova, S. L. Castro and M. C. Marcucci, Apidologie, 2000, 31, 3-15.

2 A. H. Banskota, Y. Tezuka, I. K. Adnyana, K. Midorikawa, K. Matsushige, D. Message, A. A. G. Huertas and S. Kadota, J. Ethnopharmacol., 2000, 72, 239-246.

3 R. O. Orsi, J. M. Sforcin, S. R. C. Funari and V. Bankova, Int. Immunopharmacol., 2005, 5, 359-368.

4 J. Y. Fu, Y. Xia and Y. Zheng, Biomed. Environ. Sci., 2004, 17, 469-475.

5 R. A. Laskar, I. Sk, N. Roy and N. A. Begum, Food Chem., 2010, 122, 233-237.

6 J. A. Mendiola, P. J. Martín-Alvarez, F. J. Señoráns, G. Reglero, A. Capodicasa, F. Nazzaro, A. Sada, A. Cifuentes and E. Ibañez, J. Agric. Food Chem., 2010, 58, 787-792.

7 C. van Loveren, Z. Broukal and E. Oganessian, Eur. J. Nutr., 2012, 51, S15-S25.

8 S. K. Han, K. Yamauchi and H. K. Park, Microbios, 2001, 105, $71-75$. 
9 R. D. Vargas-Sánchez, G. R. Torrescano-Urrutia, E. AcedoFélix, E. Carvajal-Millán, A. F. González-Córdova, B. VallejoGalland, M. J. Torres-Llanez and A. Sánchez-Escalante, J. Food Sci., 2014, 79, C1499-C1504.

10 Y. Aliyazicioglu, S. Demir, I. Turan, T. N. Cakiroglu, I. Akalin, O. Deger and A. Bedir, Acta Biol. Hung., 2011, 62, 388-396.

11 G. S. Santos, S. Tsutsumi, D. P. Vieira, P. Bartolini and K. Okazaki, Mutat. Res., 2014, 762, 17-23.

12 M. S. Camargo, A. M. Prieto, F. A. Resende, P. K. Boldrin, C. R. Cardoso, M. F. Fernández, J. M. Molina-Molina, N. Olea, W. Vilegas, O. Cuesta-Rubio and E. A. Varanda, BMC Complementary Altern. Med., 2013, 13, 201.

13 Y. C. Tsai, Y. H. Wang, C. C. Liou, Y. C. Lin, H. Huang and Y. C. Liu, Chem. Res. Toxicol., 2012, 25, 191-196.

14 G.-C. Yen, P.-D. Duh, H.-L. Tsai and S.-L. Huang, Biosci., Biotechnol., Biochem., 2003, 67, 1215-1222.

15 F. Marques, F. Azevedo, B. Johansson and R. Oliveira, Food Chem. Toxicol., 2011, 49, 1361-1366.

16 V. L. Singleton, R. Orthofer and R. M. Lamuela-Raventós, Methods Enzymol., 1999, 299, 152-178.

17 R. G. Woisky and A. Salatino, J. Apic. Res., 1998, 37, 99-105. 18 C. Rice-Evans, N. Miller and G. Paganga, Trends Plant Sci., 1997, 2, 152-159.

19 A. Hatano, T. Nonaka, M. Yoshino, M.-R. Ahn, S. Tazawa, Y. Araki and S. Kumazawa, Food Sci. Technol. Res., 2012, 18, 577-584.

20 J. C. Silva, S. Rodrigues, X. Feás and L. M. Estevinho, Food Chem. Toxicol., 2012, 50, 1790-1795.

21 H. Yang, Y. Dong, H. Du, H. Shi, Y. Peng and X. Li, Molecules, 2011, 16, 3444-3455.

22 S. M. Alencar, T. L. C. Oldoni, M. L. Castro, I. S. R. Cabral, C. M. Costa-Neto, J. A. Cury, P. L. Rosalen and M. Ikegaki, J. Ethnopharmacol., 2007, 113, 278-283.

23 F. Pellati, G. Orlandini, D. Pinetti and S. Benvenuti, J. Pharm. Biomed. Anal., 2011, 55, 934-948.

24 S. I. Falcão, N. Vale, P. Gomes, M. R. Domingues, C. Freire, S. M. Cardoso and M. Vilas-Boas, Phytochem. Anal., 2012, 24, 309-318.

25 C. Gardana, M. Scaglianti, P. Pietta and P. Simonetti, J. Pharm. Biomed. Anal., 2007, 45, 390-399.

26 T. Farooqui and A. A. Farooqui, Front. Biosci., Elite Ed., 2012, 4, 779-793.

27 S. C. Sahu and G. C. Gray, Food Chem. Toxicol., 1997, 35, 443447.

28 C. Santos-Buelga, S. González-Manzano, M. Dueñas and A. M. González-Paramás, in Recent Advances in Polyphenol
Research, ed. V. Cheynier, P. Sarni-Machado and S. Quideau, Wiley-Blackwell, 2012, ch. 11, pp. 249-286.

29 M. J. Valente, A. F. Baltazar, R. Henrique, L. Estevinho and M. Carvalho, Food Chem. Toxicol., 2011, 49, 86-92.

30 R. C. Calhelha, S. Falcão, M. J. R. P. Queiroz, M. Vilas-Boas and I. C. F. R. Ferreira, BioMed Res. Int., 2014, 897361.

31 I. Valença, F. Morais-Santos, V. Miranda-Gonçalves, A. M. Ferreira, C. Almeida-Aguiar and F. Baltazar, BMC Complementary Altern. Med., 2013, 13, 184.

32 H. Fokt, A. Pereira, A. M. Ferreira, A. Cunha and C. Aguiar, Current Research, Technology and Education Topics in Applied Microbiology and Microbial Biotechnology, 2010, vol. 1, pp. 481-493.

33 N. Oršolić, Journal of ApiProduct and ApiMedical Science, 2010, 2, 1-20.

34 D. C. Tavares, G. R. M. Barcelos, L. F. Silva, C. C. C. Tonin and J. K. Bastos, Toxicol. in Vitro, 2006, 20, 1154-1158.

35 A. R. Collins, A. A. Ozcoz, G. Brunborg, I. Gaivão, L. Giovannelli, M. Kruszewsk, C. C. Smith and R. Stetina, Mutagenesis, 2008, 23, 143-151.

36 D. Lisicic, V. Benkovic, D. Dikic, A. S. Blazevic, J. Mihaljevic, N. Orsolic and A. H. Knezevic, Cancer Biother. Radiopharm., 2014, 29, 62-69.

37 J. Li, M. Mottamal, H. Li, K. Liu, F. Zhu, Y. Y. Cho, C. P. Sosa, K. Zhou, G. T. Bowden, A. M. Bode and Z. Dong, Carcinogenesis, 2012, 33, 459-465.

38 M. S. Weng, Y. S. Ho and J. K. Lin, Biochem. Pharmacol., 2005, 60, 1815-1827.

39 S. U. Mertens-Talcott, S. T. Talcott and S. S. Percival, J. Nutr., 2003, 133, 2669-2674.

40 J. W. Fahey and T. W. Kensler, Chem. Res. Toxicol., 2007, 20, 572-576.

41 L. Moreira, L. G. Dias, J. A. Pereira and L. Estevinho, Food Chem. Toxicol., 2008, 46, 3482-3485.

42 M. G. Miguel, S. Nunes, S. A. Dundlen, A. M. Cavaco and M. D. Antunes, Food Chem. Toxicol., 2010, 48, 3418-3423.

43 S. I. Falcão, N. Vale, P. Cos, P. Gomes, C. Freire, L. Maes and M. Vilas-Boas, Phytother. Res., 2014, 28, 437-443.

44 T. Cigut, T. Polak, L. Gasperlin, P. Raspor and P. Jamnik, J. Agric. Food Chem., 2011, 59, 11449-11455.

45 T. Petelinc, T. Polak, L. Demsar and P. Jamnik, PLoS One, 2013, 8, e56104.

46 R. C. von Borstel and J. A. Higgins, Mutat. Res., 1998, 402, 321-329. 